\title{
Stress, Health and Coping Resources of Chinese Pathological Gamblers' Spouses
}

\author{
Kai Chung Leung, Irene Lai Kuen Wong*, Kam Mei Lau, Sau Ching Yeung \\ Department of Applied Social Sciences, The Hong Kong Polytechnic University, \\ Hung Hom, Kowloon, Hong Kong \\ *Corresponding author; email: ssilkw@inet.polyu.edu.hk
}

\begin{abstract}
Excessive gambling negatively impacts the lives of gamblers' spouses. This study investigated stressful life events, perceived stress, coping resources and health risks of 10 spouses recruited from two treatment facilities. In semi-structured interviews, the Social Readjustment Rating Scale identified life events encountered in the past year. The 12-item General Health Questionnaire assessed psychiatric impairment of the participants who also answered questions on physical symptoms and emotional problems. Open-ended questions gathered information on coping resources. The interviews were audio-taped and transcribed for thematic analysis. Replicating previous research results, the spouses disclosed marital, social, financial and vocational stresses related to gamblers' disordered gambling. The majority utilized both formal and informal help, internal and external coping resources to deal with the adverse circumstances. Many reported significant symptoms of physical, emotional and mental health problems. Perceived stress, but not the number of negative life events, correlated significantly with physical and psychiatric symptoms. Only positive beliefs as a type of coping resources were inversely correlated with pathology. The study findings have implications for interventions and future research.
\end{abstract}

Key words Coping $\cdot$ Health Outcomes $\cdot$ Problem Gambling $\cdot$ Spouse $\cdot$ Stress

\section{Introduction}

Gambling in Chinese communities has strong cultural roots. Approximately $80 \%$ of the Hong Kong residents aged 15 to 64 years reported gambling in the past year. The majority play for enjoyment, but 1.8 to $2.2 \%$ are addicted to gambling (University of Hong Kong, 2005; Wong \& So, 2003). Pathological gamblers commonly experience damage to health and significant relationships, and disruption in vocational and or educational pursuits (Lesieur, 1996; Hong Kong Polytechnic University, 2001). Not only do the 
gamblers themselves suffer, their immediate social environments and the larger community are also adversely affected (Ciarrocchi \& Reinert, 1993; Productivity Commission, 1999). Earlier studies revealed that for every pathological gambler, at least 5 to 10 people are negatively impacted (Ladouceur, 1993; Lobsinger \& Beckett, 1996; Productivity Commission, 1999). Obviously, the gambler's marital or de facto partner is one of the most severely affected victims (Ciarrocchi \& Reinert, 1993; Ferland et al., 2008). Partner research is scarce and often not adequately theorydriven (Patford, 2009). Much of the currently available information comes from clinical observations.

A brief review of the literature (Abbott, Cramer, \& Sherrets, 1995; Grant Kalischuk \& Cardwell, 2004; Grant Kalischuk, Nowatzki, Cardwell, Klein, \& Solowoniuk, 2006; Lesieur, 1996; Lorenz \& Shuttlesworth, 1983; Patford, 2009) shows that partner studies focus mainly on stressful life situations. The common stressors include financial difficulties, loss of money and personal possessions, threats and harassment from creditors, dysfunctional family relationships, and disrupted relationship with friends and relatives. In addition, there may be parenting issues, escalating familial conflicts, ineffective couple communication, physical and emotional abuse, and the need to shoulder additional responsibilities due to the gambler's deterioration in role functioning.

Research data consistently highlight the vulnerability of the partner's health. Various significant physical, emotional and psychiatric problems have been noted. The common complaints are dizziness, chronic headaches, backaches, high blood pressure, breathing difficulties and other stress-related physical symptoms (Bergh \& Kuhlhorn, 1994; Dickerson, 1995; Lorenz \& Yaffee, 1988). Emotional problems detected are fear, anxiety, sadness, anger, guilt and regret (Dickerson, 1995; Lorenz and Yaffee, 1988; Patford, 2009). Psychiatric symptoms include insomnia, panic attacks, suicidal ideation and depression (e.g., Gaudia, 1987; Lorenz \& Yaffee, 1988).

Partners employed a range of strategies to cope with the chaotic circumstances (Patford, 2009). While some were grateful for having supportive families (Patford, 2009), many were disappointed with both the formal and informal helpers (Coyne, Ellard, \& Smith, 1990; Krishnan \& Orford, 2000). They felt humiliated and unsupported (Krishnan \& Orford, 2000) because the helpers discounted their experiences, projected personal convictions (Patford, 2009), and might even influence their evaluation of the situations negatively (Liang, Goodman, TummalaNarra, \& Weintraub, 2005). Formal help is not always as useful as expected. Partners were dissatisfied with service providers' practice competence, knowledge base, medical advice and treatment, and inter-disciplinary collaboration between different organizations (Lorenz \& Yaffee, 1989).

To our knowledge, very few theory-driven studies have been specifically undertaken to explore the effects of problem gambling on the partners of pathological gamblers in Hong Kong. The present study could be regarded as an attempt to fill this research gap.

\section{Theoretical Framework and Research Hypotheses}

The stress-coping perspective provides a useful framework for investigating the impact of stress on the partners' lives (Krishnan \& Orford, 2000). Earlier 
gambler and partner studies acknowledged the value of examining stressful life circumstances (Bergevin, Gupa, Derevensky, \& Kaufman, 2006; Krishnan \& Orford, 2000; Patford, 2009). Therefore, in this study the definition of stress originated from Holmes and Rahe's (1967) work on life stress. The theorists developed the Social Readjustment Rating Scale (SRRS) to measure the impact of dramatic life changes (e.g., divorce and marital separation). Although life events correlated with illness (e.g., Holmes and Rahe, 1967; Rahe \& Arthur, 1978; Rahe, Biersner, Ryman, \& Arthur, 1972), the association is relatively weak and explains 1 to $16 \%$ of the illness only (Rabkin \& Struening, 1976; Tausig, 1982). As a result, perceived stress (i.e., perceived severity of impact associated with life events) was included to provide a more comprehensive understanding of stress. Perceived stress implies cognitive appraisal of a person-environment encounter and an evaluation of coping resources and options (Folkman \& Lazarus, 1980, 1985). Stress and coping thus become a dynamic phenomenon.

This study focused on examining coping resources (e.g., support networks, religious beliefs and morale), which have been tested to buffer the noxious influence of life stress on health (Antonovsky, 1979; Caplan, 1974; Cheung \& Lam, 1992; Cobb, 1976; Husaine, Neff, Newbrough, \& Moore, 1982; Pearlin \& Schooler, 1978). Investigation of coping resources promotes insights into the circumstances that facilitate or weaken spouses' coping ability, hence provide information for interventions.

Adopting the stress-coping perspective, this exploratory study aimed to identify stressful life events, perceived stress, coping resources and health risks affecting Chinese spouses of pathological gamblers. It was hypothesized that spouses who had encountered a larger number of stressful life events or experienced higher levels of perceived stress would exhibit more symptoms related to physical, emotional and mental health problems. It was also hypothesized that spouses who possessed more coping resources and perceived greater benefits from using them would experience less intense perceived stress and exhibit fewer illness symptoms. The last objective was to elucidate the relationship between stress, coping resources and health outcomes. We expected coping resources would reduce the intensity of perceived stress and the number of illness symptoms. The study results could also have implications for services and directions for future research.

\section{Method \\ Participants}

The participants were recruited from two treatment facilities. The study was conducted in Hong Kong during the period of November 2009 to March 2010. Women were eligible to participate if their current or ex-husband had been identified as pathological gamblers by the referring agencies in the year prior to the study.

All the participants were middle-aged women, with a mean age of 41.8 years $(S D=4.0$; range, 36-48 years). One had just divorced her husband, another had launched marital separation proceedings, while the others (8/10) maintained a marital relationship with the pathological gamblers. On average, their marital relationships $(n=10)$ lasted 17 years $(M=17.1, S D=6.0)$. With the exception of one participant, all of them had children aged between 6 and 17 years; two had 
3 children, three had 2 children, and four had one child. Three interviewees had attended junior high school, and seven had completed their senior high school education.

Four were housewives, one was unemployed and five were working full-time; one worked as a cashier, one was a program assistant, two were clerks, and one was a secretary. Three earned a monthly household income of $\mathrm{HK} \$ 12,000-\mathrm{HK} \$ 17,000$, three earned HK\$20,000-HK\$21,000, two earned HK\$30,000-HK\$32,000, one was living on personal savings, and one was receiving public assistance of around $\mathrm{HK} \$ 11,500$ for the whole family. With the exception of two women, eight knew their husbands had been involved in gambling activities when they were dating. On average, their spouses had gambled for 25 years $(S D=6.2)$ and exhibited symptoms of excessive gambling for 7 to 30 years. The total amount of gambling debts reported by the gamblers themselves ranged from $\mathrm{HK} \$ 70,000$ to $\mathrm{HK} \$ 8,000,000$ $(M=\mathrm{HK} \$ 1,647,000 ; S D=2,413,379.6)$.

\section{Instruments}

In this exploratory study, a combination of validated instruments and open-ended questions were used to address the research questions. All the participants were interviewed face-to-face for approximately 3 hours by a pair of researchers using a semi-structured questionnaire. The interviews were audio-taped for subsequent transcription for data analysis. Written consent from the participants was obtained after providing a full explanation of the study objectives and procedures, and assuring anonymity.

There were altogether five parts in the semi-structured questionnaire:

1. A brief demographic questionnaire was used to collect information on the participant's age, martial status, education level, occupation and monthly household income.

2. Holmes and Rahe's (1967) SRRS, which consists of a list of questions about 43 life stresses, was used to identify stressful life events encountered by the spouses over the previous 12 months. A question was added (Did you come across any other stressful life circumstances, not included in these questions?). This allowed inclusion of stressors that had not been listed. The original scoring method of summing all the "Life Change Units" (e.g., "100" for death of a spouse) was not used because we did not have enough information to determine the Life Change Units to be assigned to the new life events. A new scoring method was invented. Spouses were instructed to rate the perceived severity of stress of each life event encountered on a 4 -point scale $(0=$ none, 1 = somewhat, 2 = quite a bit, 3 = a great deal).

Two summary scores were created: the Life Event Frequency Score and the Total Perceived Stress Score. The former indicates the total number of stressful life events experienced by a respondent, and the latter estimates the overall perceived impact of these life event stressors. Since 18 stressful life events were detected in the study, Total Perceived Stress Scores ranged from 0 to 54, whilst the median was 27 . Low perceived stress was indicated by a score of 0 to 18 , scores for moderate levels of perceived stress were between 19 and 36, and high levels were between 37 and 54 . 
3. Open-ended questions gather information on coping resources utilized in the past year (e.g., How would you describe your experience in seeking professional help, say from counselors or doctors? What about your experience in seeking help from the non-professionals including friends and family?) The spouses were also asked to evaluate the effects or benefits of the coping resources on a 4-point scale $(0=$ no effects at all, $1=$ low perceived effects, $2=$ moderate perceived effects, $3=$ high perceived effects).

4. The 12-item General Health Questionnaire (GHQ-12) (Goldberg, 1972) detected psychiatric impairment. This short version was a valid and reliable instrument (Goldberg et al., 1997), and works as well as longer versions. Adopting the GHQ-12 scoring method (0-0-1-1), total scores ranged from 0 to 12. The threshold for case detection was 2 or 3 (Goldberg et al., 1997). A more restrictive cutoff (i.e. a score of 3) was employed to reduce false positives. Both the GHQ-12 and the SRRS were forward- and back-translated from English to Chinese by a bilingual clinician.

5. The spouses were asked to report any physical symptoms (e.g., headache and palpitation) and emotional distress experienced during the past 12 months (e.g., feeling irritable and anxious). For each endorsed symptom, the response could be coded as seldom (1), sometimes (2) and often (3). Lastly, spouses were asked to describe their self-perceived overall health status $(4=$ excellent, 3 = good, 2 = fair, 1 = poor).

\section{Statistical analyses}

Thematic analysis was undertaken to identify the common themes generated from the interview (qualitative) data (Miles \& Huberman, 1994). Using the SPSS (version 16), statistical analysis of the quantitative data generated from the SRRS and the GHQ-12 was carried out. Results were marked significant at $p<0.05$.

\section{Results}

\section{Stressful life events}

Altogether 18 stressful life events were reported by the participants. Ten stressors were pre-selected from the SRRS (Holmes \& Rahe, 1967), and eight were newly disclosed by the spouses (Table 1). On average, the respondents encountered 8.5 stressful life events $(S D=3.1)$ in the past year. One spouse experienced only 5 life events while another detailed 14 . At least half of the sample $(n=5)$ reported having experienced the following negative life events in the previous year: change in financial state (10/10), increases in frequency of arguments $(10 / 10)$, gambling debts $(10 / 10)$, children exhibiting emotional or behavioral problems $(8 / 10)$ (e.g., runaway from home, substance abuse, suicidal attempts), change in living conditions (8/10), threats of divorce $(7 / 10)$, threats and harassment from gambler's creditors or loan sharks $(7 / 10)$, trouble with in-laws $(5 / 10)$, change in residence $(5 / 10)$, and change in recreation $(5 / 10)$.

The less frequently reported life stresses included trouble with significant others like parents and siblings (4/10), change in social activities (4/10), hiding away $(3 / 10)$, warnings from an employer $(2 / 10)$, divorce $(1 / 10)$, marital separation $(1 / 10)$, dismissal from work $(1 / 10)$, and resignation from work due to gamblers' problems $(1 / 10)$. 
Table 1. Stressful life events and perceived stress reported by the respondents $(N=10)$

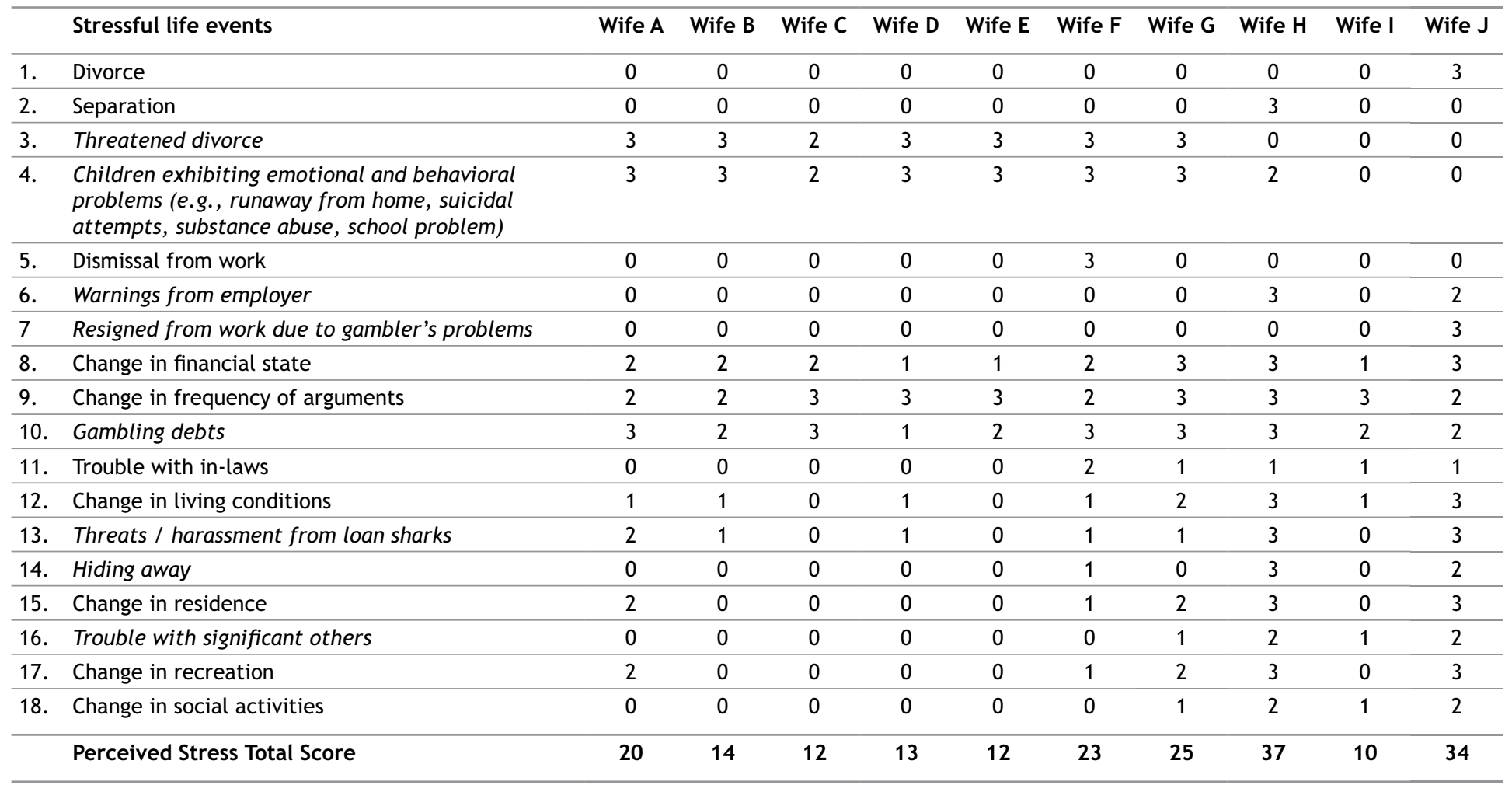

Note. 0 = life event not endorsed; 1 = life event perceived as somewhat stressful; 2 = quite a bit stressful; $3=$ a great deal stressful. New life events reported by spouses are in italics. 


\section{Perceived stress}

Five women experienced a relatively low level of perceived stress (Table 1), four reported a moderate level of perceived stress, and one had a score of 37 suggesting a high level. In this sample, the 10 most stressful life events rated in descending order were: divorce, separation, dismissal from work, resignation from work due to the gambler's problems, a threatened divorce, children's behavioral and emotional problems, frequent arguments with the gambler, warnings received from the employer, gambling debts, and change in residence due to the gambler's problems.

\section{Formal help}

Formal help was one of the significant resources utilized by the spouses to cope with the stressful circumstances. The majority $(9 / 10)$ knew that there was treatment for the gamblers (Table 2) but were less aware of counseling services for the gambler's spouses and other close family members (5/10). Only two spouses acknowledged the benefits of medication in alleviating depression and suicidal ideation. Most did not find medical treatment and professional counseling as useful as they had expected (8/10). They were anxious about the side-effects of medication, and disliked the stigma associated with psychiatric and psychosocial treatment. None was clear about how they could cooperate with professional helpers to facilitate change and recovery of the gambler.

Many appreciated the patience and support of counselors, especially during crises (8/10) (e.g., harassment from loan sharks and suicidal attempts). However, they had no ideas of the counselor's intervention plan and strategies, and were not sure if their husbands could benefit from the services. They expected and proposed more intensive couple counseling (at least twice a month), which might have strengthened marital communication and problem resolution about family finances, debt management, parenting and child welfare issues. They felt offended when peer counselors or service professionals suggested divorce or separation to avoid further harm.

\section{Support from family}

Many respondents described their maiden family as somewhat supportive (6/10), two found familial support moderately effective, one was very grateful to her family which was extremely helpful in providing practical and emotional support. Only one spouse complained of having received no support at all from her maiden family. Despite the benefits derived from familial support, there were persistent costs and pressures. Four claimed that they lost face and dignity, and felt pressured when their family members (parents and siblings) advised them to leave their spouse to protect themselves and their children. Some were very upset when they recalled how their parents or siblings hinted that the couple's relationship would dissolve one day (3/10). Some family members actually disapproved the marriage with the gambler right at the beginning $(2 / 10)$. Some took the initiative to seek professional advice or consider joining self-help groups, only when informal support gradually diminished $(8 / 10)$. 


\begin{tabular}{|c|c|c|c|c|c|c|c|c|c|c|}
\hline & Wife A & Wife B & Wife C & Wife D & Wife E & Wife $F$ & Wife G & Wife $\mathrm{H}$ & Wife I & Wife $\mathrm{J}$ \\
\hline Emotional support from friends & 0 & 0 & 1 & 0 & 0 & 3 & 0 & 1 & 2 & 1 \\
\hline Religious beliefs & $0(x)$ & $0(x)$ & $0(x)$ & $0(x)$ & $0(x)$ & $0(\mathrm{x})$ & 1 & 1 & 3 & $0(x)$ \\
\hline Positive beliefs and attitude & 2 & 2 & 0 & 2 & 1 & 0 & 0 & 0 & 3 & 0 \\
\hline $\begin{array}{l}\text { Professional help and support (e.g., medication and } \\
\text { counseling) }\end{array}$ & 0 & 0 & 0 & 0 & 2 & 0 & 1 & 0 & 0 & 0 \\
\hline Total score & 9 & 8 & 8 & 5 & 3 & 11 & 3 & 4 & 13 & 3 \\
\hline
\end{tabular}

Note. $\mathrm{x}=$ coping resource not available; $0=$ no perceived effects; $1=$ low level of perceived effects; $2=$ moderate level of perceived effects; $3=$ high level of perceived effects. 


\section{Support from friends}

Three spouses remarked that their friends were somewhat helpful because they acted as listeners and were quite sympathetic, but five others found themselves almost socially isolated. Friends simply disappeared or distanced themselves from the respondents when it was disclosed that the husband was a gambling addict $(5 / 10)$. One spouse admitted that she lost many friends who had lent money to her for her husband's gambling debts, although two of her friends were fairly understanding and quite helpful. She worried that she might lose their friendship one day if forced to borrow money from them again. Only one spouse was proud of her best friends' unfailing support. They visited her when she fell sick, and encouraged her not to give up. They found information on gambling treatment and self-help organizations for her. Many spouses were grateful to their friends who had offered social and financial help when they felt desperate $(6 / 10)$. However, they did feel humiliated when friends criticized their tolerance and ineffective coping with the husband $(4 / 10)$.

\section{Religious affiliation and beliefs}

The majority of the spouses did not have any religious affiliations or beliefs (7/10). Two Christians recognized religious beliefs were fairly effective in restoring hope when they were very disturbed and upset. A wife claimed that religious beliefs and God empowered her to face up to all the difficulties and tests in life. From a religious perspective, she found meaning in all her sufferings, and believed that there would be help and that change was possible.

\section{Positive beliefs and attitudes towards problem solving}

Half of the participants became pessimistic about the gambler's dedication and ability to change (5/10). They felt gloomy about the future partly because they held a negative view on overcoming their distressing circumstances. They became more frustrated and down-hearted with such negative thoughts. Another five sustained a sense of hope in life, by adopting an optimistic attitude towards problem resolution. They experienced the beneficial effects of upholding positive thoughts and beliefs (e.g., I can fix the problem. Tomorrow will be brighter than today. I shall overcome these challenges. There is still hope of making changes. If he won't change, I shall be able to learn and change myself, etc). They realized how they were empowered with positive thoughts and attitudes, and became more patient and less depressed in adversity. Some of them even talked to themselves in a positive manner, and encouraged themselves to be strong. Then, they often felt better and their headaches would fade gradually.

\section{Access to financial help}

All the spouses recognized the importance of being able to identify and gain access to sources of both private and public economic assistance. The quality of family life diminished tremendously due to financial difficulties. Social life and recreational activities were seriously affected, and children were often deprived from joining fee-charging interest group meetings and school activities (excursions and study tours). Half of the participants reported differing degrees of confidence in being 
able to locate possible sources of monetary help, and the other five said that they had exhausted all possible sources of financial help.

\section{Energy and morale}

With the exception of three spouses, they all described themselves as having varying amounts of physical strength and morale to cope with the demands and hassles of daily life; two had remarkable good morale, three sustained fair morale and two endured relatively low morale.

An estimation of the overall impact of all the coping resources utilized was made by summing up the perceived effect scores associated with each type of coping resource. Total scores range from 0 to 21; a score of 0 indicated no benefits at all, whilst 1-7 suggested low perceived effects, 8-14 represented moderate perceived effects, and 15-21 implied a high level of perceived beneficial impact. Half of the sample attained a score of 1-7, suggesting low levels of perceived benefits. Five scored within the range of 8-14, implying that the coping resources were of moderate perceived impact.

\section{Physical health symptoms}

Many spouses suffered frequent headaches (7/10) and stomach-aches (7/10). Several complained of poor appetite $(4 / 10)$, and significant weight loss (4/10). Four exhibited symptoms of anorexia nervosa. Three experienced chronic fatigue and one had a cancer.

\section{Emotional distress}

The majority were distressed with chronic anxiety (10/10), fear (8/10), depression and sadness $(8 / 10)$, and irritability $(8 / 10)$. Half of them felt desperate and had suicidal ideation $(5 / 10)$ or attempted suicide $(3 / 10)$, and three were often in low spirit.

\section{Mental health symptoms}

With the exception of one participant, all the spouses $(9 / 10)$ scored above the threshold of " 3 " on the Chinese GHQ-12 (mean score $=7.9, S D=3.0$ ) indicating psychiatric disturbance. The frequently reported symptoms were: inability to concentrate $(9 / 10)$, sleep disorder $(9 / 10)$, feeling depressed $(9 / 10)$, being under strain (9/10), feeling unhappy (8/10), not overcoming difficulties $(7 / 10)$, not enjoying activities $(7 / 10)$, inability to face problems $(6 / 10)$, not playing a useful part $(5 / 10)$, feeling worthless $(5 / 10)$, inability to make decisions $(4 / 10)$, and loss of self-confidence $(2 / 10)$.

\section{Self-perceived health}

Three women commented that they were not healthy physically, emotionally and mentally. Two wives described their health as poorer than that of average women. Three noted that their overall health status was fair, and two remarked that it was good. 


\section{Relationship between stress and illness symptoms}

The correlation results based on Kendall's tau-b method indicated a significant positive association between perceived stress and symptoms of physical illness $(r$ $=0.53, p<0.05)$ and mental health problems $(r=0.65 ; p<0.05)$. The relationship between the number of stressful life events and all the symptom variables was nonsignificant.

\section{Relationship between coping and illness symptoms}

Correlational analyses based on Kendall's tau-b method yielded an inverse, nonsignificant relationship between coping resources (including the total number of such resources utilized and their perceived effects) and all the symptoms and stress variables. Only perceived impact of positive beliefs or attitudes towards problem resolution was inversely and significantly associated with symptoms of physical illness $(r=-0.80, p<0.01)$ and emotional problems $(r=-0.48, p<0.05)$. There was no significant relationship between other types of coping resources and health outcomes.

\section{Discussion}

This study increased our understanding of life stresses, coping resources and health risks affecting wives of Chinese pathological gamblers. Contrary to earlier research on life events (e.g., Holmes and Rahe, 1967; Rahe et al., 1972; Rahe \& Arthur, 1978), the hypothesis on stress and illness was partially confirmed (i.e. in terms of perceived stress only), but not in terms of the number of negative life events. Consistent with previous health data (e.g., Cohen, 1985; Cohen, Kamarck, \& Mermelstein, 1983; Lazarus \& Folkman, 1984), perceived stress turned out to be a significant predictor of pathology, with correlation coefficients exceeding 0.5. The deleterious effects of perceived stress on health outcomes have been documented (e.g., Cohen et al., 1983; Linn, 1985). Whilst inclusion of perceived stress in future studies is recommended, we do not have evidence to determine whether "Life Change Units" do or do not associate with illness symptoms. More research is needed before conclusion relating to life stress and illness can be made, although health researchers have pointed out a relatively weak association between life stress and pathology (Rabkin \& Struening, 1976; Tausig, 1982).

Since many stressful life events disclosed by the spouses were unique to families victimized by excessive gambling (e.g., gambling debts and threats from loan sharks), it appears useful to develop a life event inventory specifically to monitor life stresses experienced by pathological gamblers, their partners and other close family members. Such efforts may also enable further discussion and offer comparisons between negative life events and perceived stress in health research.

This study did not provide support for the stress-buffering hypothesis of coping resources. Among all the coping resources, only positive beliefs or attitudes towards problem solving were inversely and significantly correlated with physical symptoms and emotional disturbance (but not psychiatric problems). Attitudes and belief systems are critical for cognitive appraisal and coping (Pearlin \& Schooler, 1978), and the study results suggest the need of changing negative beliefs and attitudes, and promoting problem solving techniques. Cognitive-behavioral 
therapy seems to be the most effective treatment option (Ladouceur, Boisvert, \& Dumont, 1994; Sylvain, Ladouceur, \& Boisvert, 1997). Future research may examine whether coping strategies rather than coping resources could be a buffer against the detrimental effects of stressful life events and perceived stresses on health outcomes. This study only focused on exploring coping resources, and did not include coping strategies.

Replicating previous research results (e.g., Bergh \& Kuhlhorn, 1994; Dickerson, 1995; Dickson-Swift, James, \& Kippen, 2005; Gaudia, 1987; Lorenz \& Yaffee, 1988; Patford, 2009), the Chinese spouses of pathological gamblers were vulnerable to physical, emotional and mental health problems. We suggest that comprehensive assessment of their health status and suicidal risks should be included in the service intakes, and that early referrals for medical and psychosocial treatment should be made to safeguard against further deterioration of health.

As an exploratory investigation, only 10 wives of pathological gamblers were recruited in this study, which may have affected the external validity of the research. Study findings may not be generalized to other Asian spouses or partners who engage in support networks and service aids different from those of Chinese gamblers' wives in Hong Kong. Future research may include male partners and employ more rigorous designs (e.g., prospective and longitudinal investigations with a larger sample size). Comparison groups may also be included (e.g., spouses and partners of social gamblers and non-gamblers). In the recent decade, evidencebased knowledge of Asian gamblers' distress and health risks is growing, for example, via research conducted at the Hong Kong Polytechnic University (2001), and the University of Hong Kong (2005). Limited theory-driven research on gamblers' family members has been conducted. More work on excessive gamblers' families in Asian communities is particularly needed to fill this research gap.

\section{Acknowledgments}

The authors thank the treatment facilities for providing help in recruiting the participants. A substantial debt of gratitude is owed to anonymous reviewers.

\section{References}

Abbott, D. A., Cramer, S. L., \& Sherrets, S. D. (1995). Pathological gambling and the familypractice implications. Families in Society, 76, 213-219.

Antonovsky, A. (1979). Health, stress and coping. San Francisco: Jossey-Bass.

Bergevin, T., Gupa, R, Derevensky, J, \& Kaufman, F. (2006). Adolescent gambling: Understanding the role of stress and coping. Journal of Gambling Studies, 22, 195-208.

Bergh, C., \& Kuhlhorn, E. (1994). Social, psychological and physical consequences of pathological gambling in Sweden. Journal of Gambling Studies, 10, 275-285.

Caplan, G. (1974). Support systems and community mental health. New York: Behavioral Publications.

Cheung, S. K., \& Lam, A. (1992). Report on the study of adolescent depression. Hong Kong: The Boys and Girls Clubs Association of Hong Kong.

Ciarrocchi, J. W., \& Reinert, D. F. (1993). Family environment and length of recovery for married male members of gamblers anonymous and female members of GamAnon. Journal of Gambling Studies, 9, 341-352.

Cobb, S. (1976). Social support as a moderator of life stress. Psychosomatic Medicine, 38, 300-314. 
Cohen, F. (1985). Stress and bodily illness. In A. Monat \& R. S. Lazarus (Eds.), Stress and coping. New York: Columbia University Press.

Cohen, S., Kamarck, T., \& Mermelstein, R. (1983). A global measure of perceived stress. Journal of Health and Social Behavior, 24, 385-396.

Coyne, J. C., Ellard, J. H., \& Smith, D. A. (1990). Social support, interdependence, and the dilemmas of helping. In B. R. Sarason, I. G. Sarason, \& G. R. Pierce (Eds.), Social support: An international view (pp.129-149). New York: Wiley.

Dickerson, M. (1995). Problem gambling in Australia. Proceedings of the inquiry into the social impact of the extension of EGMs beyond casinos in Tasmania (pp.15-17). Tasmanian Council of Social Services.

Dickson-Swift, V. A., James, E. L., \& Kippen, S. (2005). The experience of living with a problem gambler: Spouses and partners speak out. Journal of Gambling Issues, 13, 1-20.

Ferland, F., Fournier, P.-M., Ladouceur, R., Brochu, P., Bouchard, M., \& Paquet, L. (2008). Consequences of pathological gambling on the gambler and his spouse. Journal of Gambling Issues, 22, 219-229.

Folkman, S., \& Lazarus, R. S. (1980). An analysis of coping in a middle-aged community sample. Journal of Health and Social Behavior, 21, 219-239.

Folkman, S., \& Lazarus, R. S. (1985). If it changes it must be a process: Study of emotion and coping during three stages of a college examination. Journal of Personality and Social Psychology, 48, 150-170.

Gaudia, R. (1987). Effects of compulsive gambling on the family. Social Work, 32, 254-256.

Goldberg, D. P. (1972). The detection of psychiatric illness by questionnaire. Maudsley Monograph No. 21. Oxford: Oxford University Press.

Goldberg, D. P., Gater, R., Sartorius, N., Ustun, T. B., Piccinelli, M., Gureje, O., \& Rutter, C. (1997). The validity of two versions of the GHQ in the WHO study of mental health illness in general health care. Psychological Medicine, 27, 191-197.

Grant Kalischuk, R., \& Cardwell, K. (2004). Problem gambling and its impact on families. Final report submitted to the Albert Alcohol and Drug Abuse Commission (AADAC). Edmonton, $\mathrm{AB}$.

Grant Kalischuk, R., Nowatzki, N., Cardwell, K., Klein, K., \& Solowoniuk, J. (2006). Problem gambling and its impact on families: A literature review. Journal of Gambling Studies, 6, $31-60$.

Holmes, T. H., \& Rahe, R. H. (1967). The Social Readjustment Rating Scale. Journal of Psychosomatic Research, 11, 213-218.

Hong Kong Polytechnic University. (2001). A study on Hong Kong people's participation in gambling activities. Hong Kong: Hong Kong Polytechnic University.

Husaine, A., Neff, J. A., Newbrough, J. R., \& Moore, M. C. (1982). The stress-buffering role of social support and personal confidence among the rural married. Journal of Community Psychology, 10, 409-426.

Krishnan, M., \& Orford, J. (2000). Gambling and the family: From the stress-coping-support perspective. International Gambling Studies, 2, 61-83.

Ladouceur, R. (1993). Jeu pathologique [Pathological gambling]. In R. Ladouceur, O. Fontaine, \& J. Cottraux (Eds.), Therapie cognitive et comportementale (pp. 123-128). Paris: Masson.

Ladouceur, R., Boisvert, J. M., \& Dumont, J. (1994). Cognitive-behavioral treatment for adolescent pathological gamblers. Behavioral Modification, 18, 230-242.

Lazarus, R. S., \& Folkman, S. (1984). Stress, appraisal, and coping. New York: Springer.

Lesieur, H. R. (1996). Costs and treatment of pathological gambling. Annals of the American Academy of Political and Social Science, 556, 153-171.

Liang, B., Goodman, L., Tummala-Narra, P., \& Weintraub, S. (2005). A theoretical framework for understanding help-seeking processes among survivors of intimate partner violence. 
American Journal of Community Psychology, 36, 71-84.

Linn, M. W. (1985). A global assessment of recent stress (GARS) scale. International Journal of Psychiatry in Medicine, 15, 47-59.

Lobsinger, C., \& Beckett, L. (1996). Odds on the break even: A practical approach to gambling awareness. Canberra: Relationships Australia, Inc.

Lorenz, V. C. \& Shuttlesworth, D. (1983). The impact of pathological gambling on the spouse of the gambler. Journal of Community Psychology, 11, 67-76.

Lorenz, V. C., \& Yaffee, R. A. (1988). Pathological gambling: Psychosomatic, emotional and marital difficulties as reported by the spouse. Journal of Gambling Behavior, 4, 13-26.

Lorenz, V. C., \& Yaffee, R. A. (1989). Pathological gamblers and their spouses: Problems in interaction. Journal of Gambling Behavior, 5, 113-126.

Miles, M. B., \& Huberman, A. M. (1994). Qualitative data analysis: An expanded source book. Newbury Park, CA: Sage.

Patford, J. (2009). For worse, for poorer and in ill health: How women experience, understand and respond to a partner's gambling problems. International Journal of Mental Health and Addiction, 7, 177-189.

Pearlin, L., \& Schooler, C. (1978). The structure of coping. Journal of Health and Social Behavior, 19, 2-21.

Productivity Commission. (1999). Australia's gambling industries. Report No. 10, AusInfo, Canberra.

Rabkin, J. G., \& Struening, E. L. (1976). Life events, stress and illness. Science, 194, 1013-1020.

Rahe, R. H., \& Arthur, R. J. (1978). Life changes and illness studies: Past history and future directions. Human Stress, 4, 3-15.

Rahe, R. H., Biersner, R. J., Ryman, D. H., \& Arthur, R. J. (1972). Psychosocial predictors of illness behavior and failure in stressful training. Journal of Health and Social Behavior, 13, 393-397.

Sylvain, C., Ladouceur, R., Boisvert, J. M. (1997). Cognitive and behavioral treatment of pathological gambling: A controlled study. Journal of Consulting and Clinical Psychology, $65,727-732$.

Tausig, M. (1982). Measuring life events. Journal of Health and Social Behavior, 23, 52-64.

University of Hong Kong. (2005). A study on Hong Kong people's participation in gambling activities. Hong Kong: The University of Hong Kong.

Wong, I. L. K., \& So, E. M. T. (2003). Prevalence estimates of problem and pathological gambling in Hong Kong. American Journal of Psychiatry, 160, 1353-1354. 